\title{
ANALISIS KEJADIAN ANGIN PUTING BELIUNG MENGGUNAKAN CITRA SATELIT HIMAWARI-8 (STUDI KASUS KOTA BOGOR, JAWA BARAT 21 SEPTEMBER 2021)
}

\section{Aqasha Raechan Anam, Sayful Amri}

Sekolah Tinggi Meteorologi Klimatologi dan Geofisika, Banten, Indonesia

Email: raechananam@gmail.com, sayful.amri@stmkg.ac.id

\begin{abstract}
Abstrak
Kejadian angin puting beliung adalah sebuah fenomena cuaca ekstrem yang terjadi di wilayah tropis seperti wilayah Indonesia. Banyaknya kejadian angin puting beliung di Indonesia menjadikan kejadian ekstrem ini menarik untuk diteliti lebih lanjut. Pada hari Kamis tanggal 21 September 2021 sekitar pukul 15.00 WIB telah dianalisis kejadian ekstrem angin puting beliung di wilayah Kota Bogor. Dilakukan analisis data Reanalysis Sea Surface Temperature (SST), curah hujan, kelembapan relatif (RH), K-indeks dan TT indeks. Dilakukan juga analisis data observasi suhu udara permukaan dan tekanan udara permukaan. Sedangkan untuk analisis citra satelit Himawari-8 dilakukan menggunakan software SATAID. Melalui analisis tersebut didapatkan bahwa nilai suhu udara permukaan dan tekanan udara permukaan menurun secara signifikan dan telah terjadi shearline pada analisis streamline angin di wilayah Kota Bogor. Sedangkan untuk analisis sea surface temperature (SST) dan kelembapan relatif (RH) berpengaruh lemah terhadap kejadian angin puting beliung. Untuk analisis $\mathrm{K}$ indeks dan TT indeks juga dihasilkan nilai sedang untuk dijadikan parameter terjadinya kejadian angin puting beliung. Selanjutnya untuk analisis citra satelit Himawari-8 melalui kanal IR, timeseries IR, dan contour menggunakan SATAID dihasilkan terdapat penebalan awan konvektif dan kenaikan suhu puncak awan saat terjadi kejadian angin puting beliung.
\end{abstract}

Kata Kunci: cuaca ekstrem; SATAID; puting beliung; reanalysis

\section{Abstract}

Tornado events are an extreme weather phenomenon that occurs in tropical areas such as Indonesia. The number of tornadoes in Indonesia makes this extreme event interesting for further investigation. On Thursday, September 21, 2021, at around 15.00 WIB, an extreme tornado event in the Bogor City area was analyzed. Reanalysis of Sea Surface Temperature (SST) data was analyzed, rainfall, relative humidity $(R H), K$-index and $T T$ index were carried out. Analysis of the observation data of surface air temperature and surface air pressure was also carried out. Meanwhile, analysis of the Himawari-8 satellite image was carried out using SATAID software. Through this analysis, it was found that the values of surface air temperature and surface air pressure decreased significantly and shearline had occurred in wind streamline analysis

$\begin{array}{ll}\text { How to cite: } & \text { Anam. A. R. \& Amri. S. (2021) Analisis Kejadian Angin Puting Beliung Menggunakan Citra Satelit } \\ & \text { Himawari-8 (Studi Kasus Kota Bogor, Jawa Barat 21 September 2021), 6 (2), Syntax Literate: Jurnal } \\ & \text { Ilmiah Indonesia } \\ \text { E-ISSN: } & \text { 2548-1398 } \\ \text { Published by: } & \text { Ridwan Institute }\end{array}$


in the Bogor City area. Meanwhile, the analysis of sea surface temperature (SST) and relative humidity (RH) has a weak effect on the occurrence of hurricanes. For the analysis of the $K$ index and the TT index, medium values are also produced to be used as parameters for the occurrence of hurricane events. Furthermore, for the analysis of Himawari-8 satellite imagery via IR channel, IR timeseries, and contour using SATAID, it is found that there is a thickening of convective clouds and an increase in cloud top temperature when a hurricane occurs.

Keywords: extreme weather; SATAID; tornado; reanalysis

Received: 2021-10-20; Accepted: 2021-11-05; Published: 2021-11-20

\section{Pendahuluan}

Indonesia merupakan salah satu negara tropis yang memiliki potensi bencana ekstrem yang besar. Cuaca ekstrem adalah kondisi cuaca dimana pengamatan unsurunsur cuaca yang teramati melebihi ambang batas yang telah ditetapkan dan pada umumnya dapat menimbulkan bencana hidrometeorologi (BMKG, 2019). Salah satu cuaca ekstrem adalah puting beliung. Puting beliung adalah sebuah fenomena angin yang berputar dengan kecepatan lebih dari 60-90 km/jam yang berlangsung sekitar 510 menit yang diakibatkan adanya perbedaan tekanan yang besar dalam area dengan skala kecil yang terjadi di sekitar awan Cumulonimbus (Sudibyakto, 2018). Dalam rentang waktu 2008-2021 puting beliung merupakan bencana dengan jumlah paling banyak setelah bencana banjir (BNPB, 2021). Kota Bogor merupakan salah satu daerah yang diterjang puting beliung pada tanggal 21 September 2021. Berdasarkan laporan sementara total 34 rumah rusak dengan 115 jiwa yang terdampak. Penulisan ini secara khusus bertujuan untuk menganalisa keadaan atmosfer dan faktor-faktor yang mempengaruhi sebelum, saat, dan sesudah kejadian puting beliung yang terjadi di Kota Bogor.

Telah dilakukan penelitian sebelumnya kejadian angin puting beliung pada di Kabupaten Bombana pada tanggal 01 Agustus 2021 dan disimpulkan bahwa pola konvergensi streamline angin, suhu muka laut (SST), indeks labilitas udara, dan pertumbuhan awan konvektif menjadi faktor pendukung terjadinya kejadian angin puting beliung (Saragih, 2020). Untuk memperkirakan cuaca tidak cukup memperhatikan parameter cuaca dalam skala regional,melainkan diperlukan juga parameter dalam skala lokal atau analisa data berdasarkan stasiun tunggal dengan memanfaatkan data hasil pengamatan sounding (Silitonga, Saragin, \& Saragih, 2017).

Penelitian ini bertujuan untuk mengembangkan hasil-hasil penelitian sebelumnya dan menambahkan faktor-faktor pendukung lain jika nantinya ada dalam penelitian ini.

\section{Metode Penelitian}

Penelitian ini dilakukan di wilayah Kota Bogor yang terletak di Provinsi Jawa Barat. Secara astronomis Kota Bogor terletak antara 10643'30"BT - 106 51'00'BT dan 30'30"LS - 6 41'00'LS. Secara administratif Sebelah Utara berbatasan dengan Kec. 
Kemang, Bojong Gede, dan Kec. Sukaraja Kabupaten Bogor. Sebelah Timur berbatasan dengan Kec. Sukaraja dan Kec. Ciawi, Kabupaten Bogor. Sebelah Barat berbatasan dengan Kec. Darmaga dan Kec. Ciomas, Kabupaten Bogor.

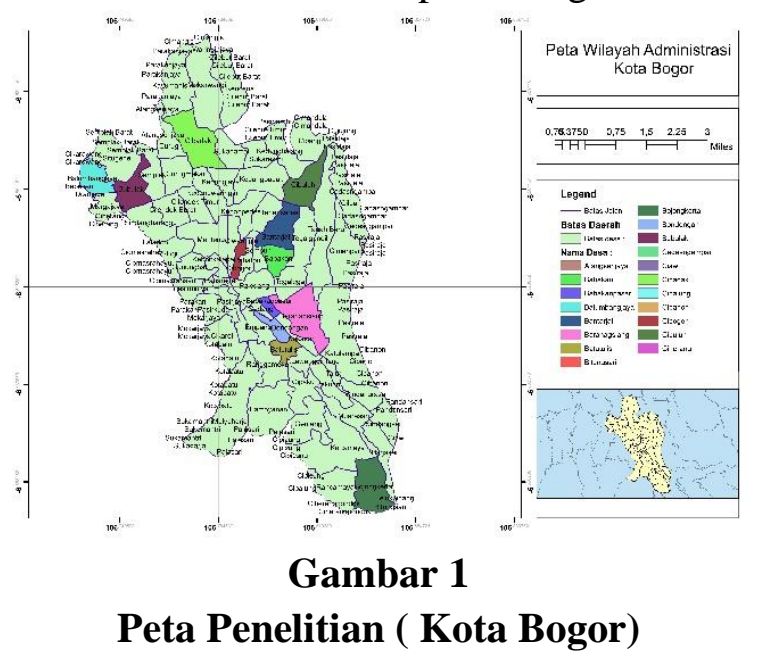

Data observasi yang digunakan adalah data AWS dari stasiun AWS Gunung Geulis Bogor, data Citra Satelit Himawari-8, dan data Monthly Reanalysis yang diambil dari situs https://cds.climate.copernicus.eu/. Data observasinya berdurasi per 10 menit untuk data AWS dan data Citra satelit. Data citra satelit Himawari-8 kemudian akan diolah menggunakan aplikasi SATAID (Satellite Animation and Interactive Diagnosis). SATAID adalah aplikasi yang dikembangkan oleh Japan Meteorology Agency (JMA) yang berfungsi untuk mengolah data citra satelit berbentuk biner menjadi gambar (Harsa, Linarka, Kurniawan, \& Noviati, 2011). Data satelit memiliki resolusi temporal yang cukup tinggi dan dapat mencakup wilayah lautan yang sangat jarang memiki data pengamatan permukaan (Prasetyo \& Pusparini, 2018).

\section{Hasil dan Pembahasan}

1. Analisis Suhu Udara Permukaan

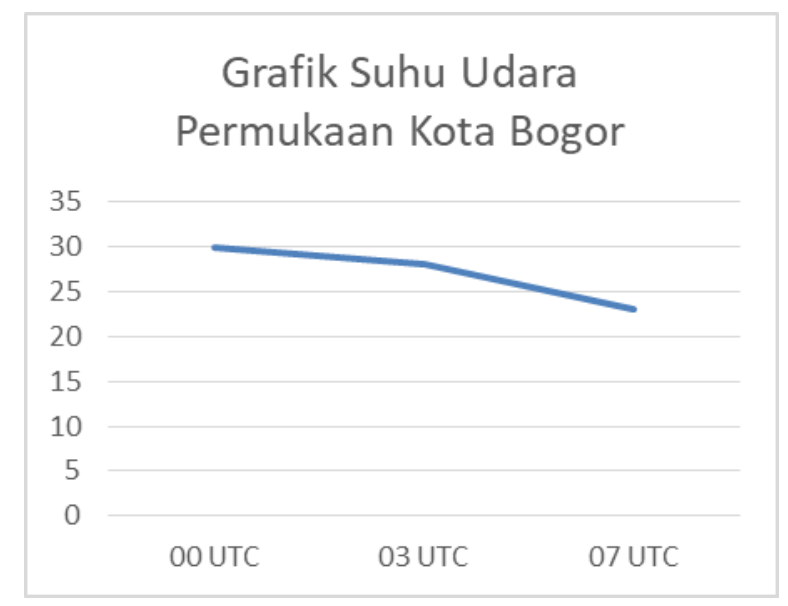

Gambar 2

Grafik Suhu Udara Permukaan Kota Bogor 
Berdasarkan gambar pengamatan suhu udara permukaan, pada tanggal 21 September 2021 terlihat bahwa terjadi penurunan suhu udara permukaan 60 menit sebelum terjadinya puting beliung yaitu pukul 13.29 - 14.29 WIB.

2. Analisis Tekanan Udara Permukaan

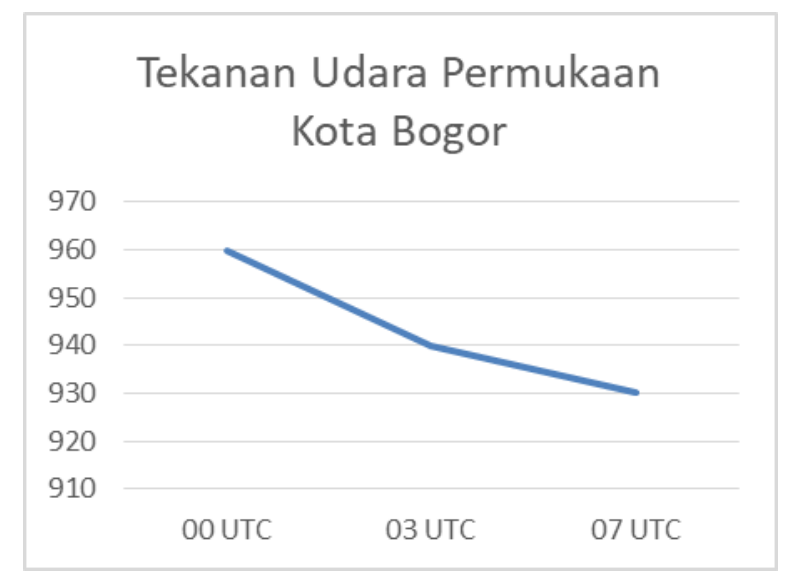

Gambar 3

Grafik Tekanan Udara Permukaan Kota Bogor

Berdasarkan gambar pengamatan suhu udara permukaan, pada tanggal 21 September 2021 terlihat terdapat penurunan tekanan udara permukaan 50 menit sebelum terjadinya puting beliung yaitu 13.09 - 14.29. Dengan adanya penurunan tekanan udara permukaan menyebabkan terjadinya massa udara yang berkumpul yang memicu terbentuknya awan konvektif seperti awan cumulonimbus.

3. Analisis Streamline Angin
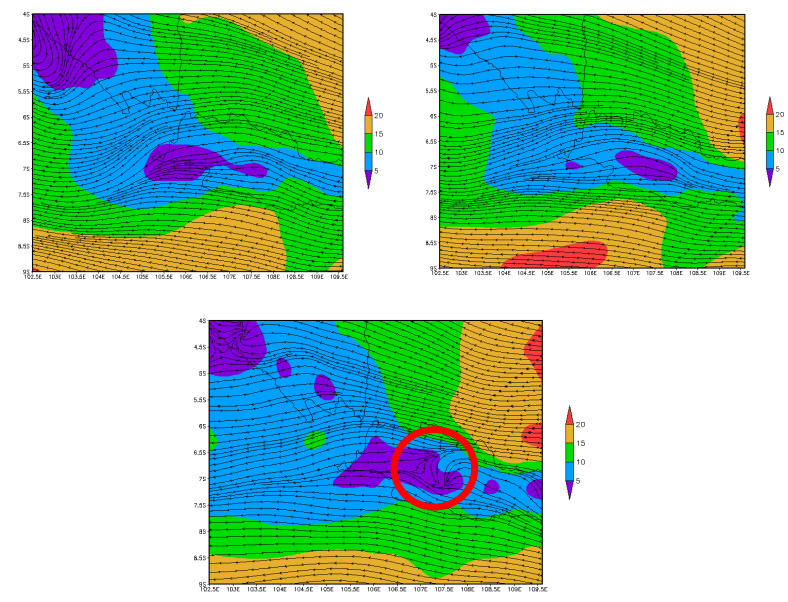

Gambar 4

Perbandingan Streamline Apada 00 UTC (kiri), 03 UTC (kanan), dan 07 UTC (bawah) sebelum kejadian angin puting beliung di Kota Bogor 
Berdasarkan gambar streamline diatas dapat dilihat pada pukul 00 UTC pola dan arah gerak anginnya masih normal seperti biasa di sekitaran wilayah Kota Bogor. Selanjutnya untuk pukul 03 UTC sudah terlihat terjadi divergensi dimana di sekitaran wilayah Kota Bogor pola dan arah gerak anginnya sudah mulai menyebar dimana biasanya daerah tersebut memiliki kecepatan angin paling kencang dibandingkan daerah sekitarnya. Selanjutnya kondisi pola dan arah gerak angin 1 jam sebelum kejadian angin puting beliung telah terjadi shearline atau belokan angin dimana kondisi angin di sekitaran wilayah Kota Bogor berbelok paling tidak $90^{\circ}$. Shearline identik dengan tempat berkumpulnya massa udara sehingga menjadi faktor pemicu pertumbuhan awan-awan konvektif penyebab cuaca buruk seperti awan cumulonimbus.

4. Analisis Suhu Muka Laut (SST)

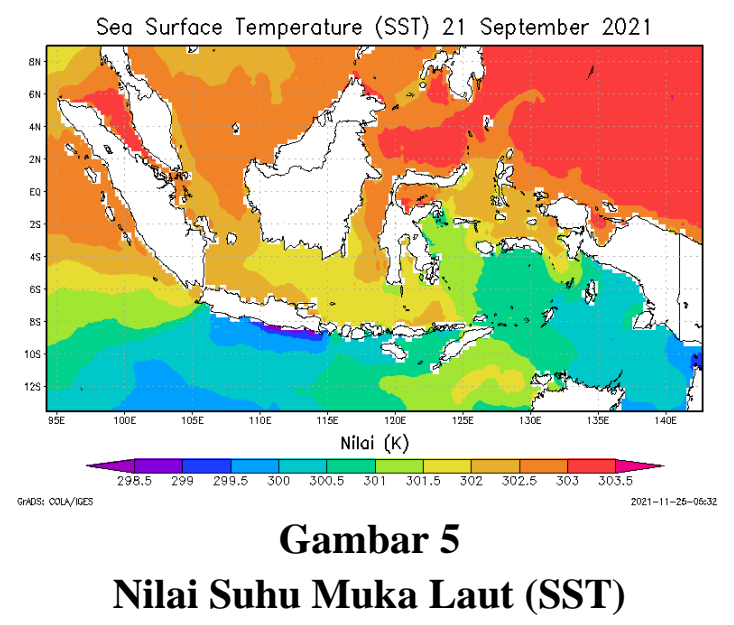

Berdasarkan analisis Suhu Muka Laut (SST) pada tanggal 21 September 2021 pada jam 00.UTC di sekitar wilayah Kota Bogor menunjukkan nilai suhu muka lautnya berkisar antara 299-303 K. Kondisi tersebut mengindikasikan terjadi potensi penguapan massa uap air. Dengan demikian dapat mempengaruhi terjadinya pembentukan awanawan konvektif di Wilayah Kota Bogor.

5. Analisis Kelembapan (RH)

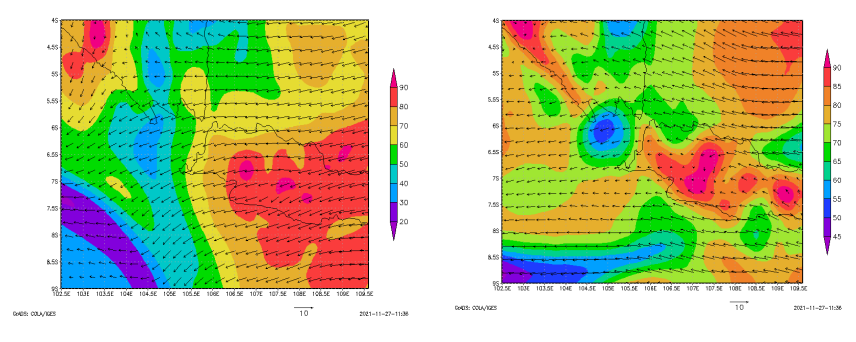




\section{Gambar 6 \\ Perbandingan nilai RH pukul 07 UTC pada lapisan $700 \mathrm{mb}$ (kiri) , $850 \mathrm{mb}$ (kanan), dan $925 \mathrm{mb}$ (bawah) sebelum kejadian angin puting beliung di Kota Bogor}

Berdasarkan analisis Kelembapan Udara (RH) di sekitar wilayah Kota Bogor pada tanggal 21 September 2021 pada pukul 07.UTC di lapisan 700 mb berkisar antara 90$100 \%$, pada lapisan $850 \mathrm{mb}$ berkisar antara 90-100\%, dan pada lapisan 925 mb berkisar antara 100-110\%. Berdasarkan nilai-nilai kelembapan udara pada setiap lapisan yang telah ditentukan di wilayah Kota Bogor dapat dikategorikan bahwa nilai kelembapan udara di atmosfer terbilang cukup tinggi sehingga dapat dijadikan faktor pendukung dalam pembentukan awan-awan konvektif (CB) di wilayah Kota Bogor.

6. Analisis K indeks dan Total-total (TT) indeks

$\mathrm{K}$ indeks merupakan parameter penduga stabilitas suhu dan kelembapan sedangkan total-total (TT) indeks merupakan parameter yang digunakan untuk dijadikan indikator cuaca buruk dan didasarkan pada data kelembapan dan suhu di lapisan $850 \mathrm{~m}, 700 \mathrm{mb}, 500 \mathrm{mb}$, dan $200 \mathrm{mb}$. Berikut merupakan tabel nilai K indeks dan total-total (TT) indeks :

Tabel 1

Tabel Nilai K Indeks dan Total-Total (TT) Indeks

\begin{tabular}{llll}
\hline \multirow{2}{*}{ Indeks } & \multicolumn{4}{l}{ Potensial Thunderstorm } & Kuat \\
\cline { 2 - 4 } & Lemah & Sedang & $>35$ \\
\hline K & $<25$ & $25-35$ & $>55$ \\
\hline TT indeks & $<45$ & $45-55$ & \\
\hline
\end{tabular}

Sumber : The Universal RAwinsonde OBservation program (RAOB)

Selanjutnya akan dianalisis nilai $\mathrm{K}$ indeks dan TT indeks di sekitaran wilayah Kota Bogor tempat terjadinya angin puting beliung. Berikut analisis peta $\mathrm{K}$ indeks dan total-total (TT) indeks.

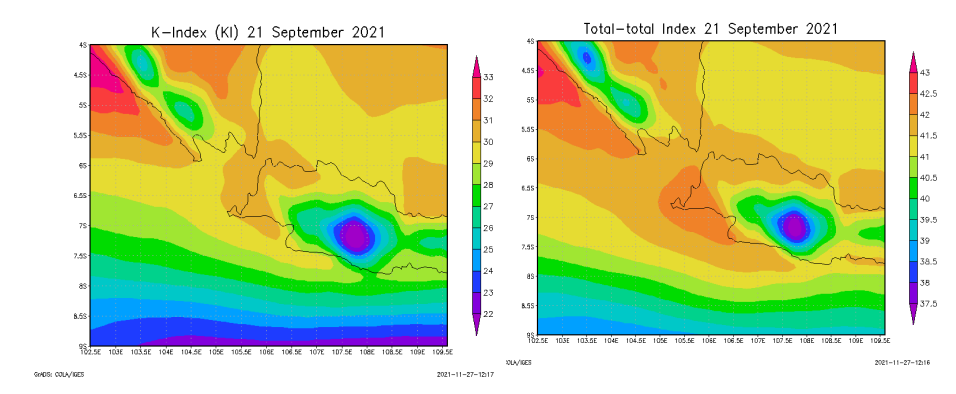

Gambar 7

Peta Nilai K-indeks dan TT indeks wilayah Kota Bogor 


\section{Analisis SATAID}

\section{1) Analisis Himawari-8 IR}

Merupakan analisis yang digunakan untuk mengetahui nilai suhu puncak awan yang didapatkan dari hasil pengamatan radiasi dengan panjang gelombang 10.4 mikrometer yang kemudian diklasifikasikan dengan pewarnaan-pewarnaan tertentu. Selanjutnya akan dilakukan analisis himawari-8 IR dengan menggunakan software SATAID untuk sekitaran wilayah Kota Bogor untuk mengetahui suhu puncak awan .

a. Tahap Pertumbuhan

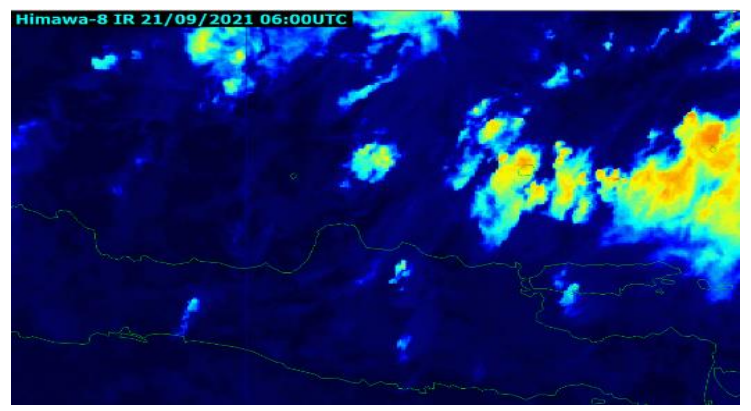

Gambar 8

\section{Himawari-8 IR Tutupan awan 06.00 UTC}

Pada tahap ini suhu lingkungan awan sama dengan suhu titik embun parsel udara sekitarnya. Keadaan dimana parsel massa udara mulai berkondensasi dikenal dengan dasar awan sedangkan keadaan dimana parsel massa udara serta butiran air tidak naik lagi disebut dengan puncak awan. Dalam gambar diatas dapat dilihat bahwa petumbuhan awan disekitaran wilayah Kota Bogor sudah mulai terlihat pada pukul 06 UTC sebelum kejadian angin puting beliung dengan ditandai adanya tutupan awan. Dapat dilihat juga tutupan awan tersebut berasal dari arah utara wilayah Kota Bogor yaitu dari laut Jawa.

b. Tahap pematangan

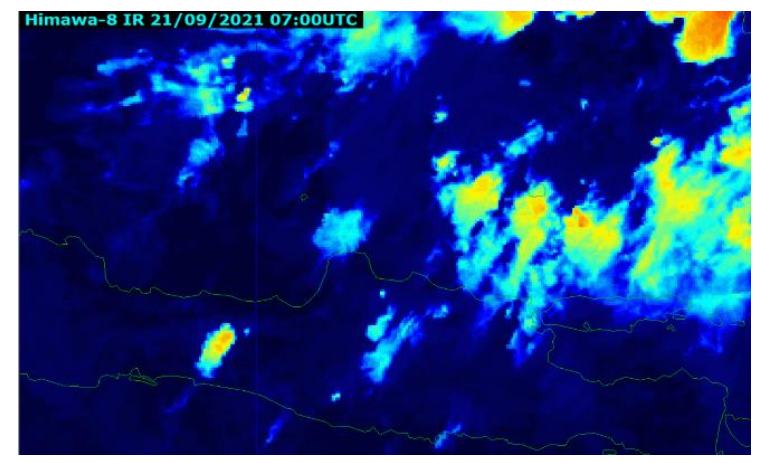

Gambar 9

Himawari-8 IR Tutupan Awan 07.00 UTC 
Pada tahap ini proses pertumbuhan awan terus terjadi. Butir -butir air didalam awan akan terus membesar melalui sebuah proses tumbukan dan penggabungan sampai butiran airnya mencapai maksimum. Pembesaran butiran air ini biasanya terjadi secara simultan, sehingga masih ada gerakan vertical dalam awan. Butir-butir air yang sudah mencapai ukuran yang besar akan turun ke level yang lebih rendah dan berada didasar awan sampai gaya berat mendominasi dari gaya-gaya lain yang ada pada butiran air tersebut. Dalam gambar tersebut terlihat bahwa proses kondensasi dan pembesaran butir air dalam awan terus berlangsung disekitaran wilayah Kota Bogor pada pukul 07 UTC sebelum terjadinya kejadian angin puting beliung dengan ditandai tutupan awan mulai banyak dan membesar.

c. Tahap Disipasi

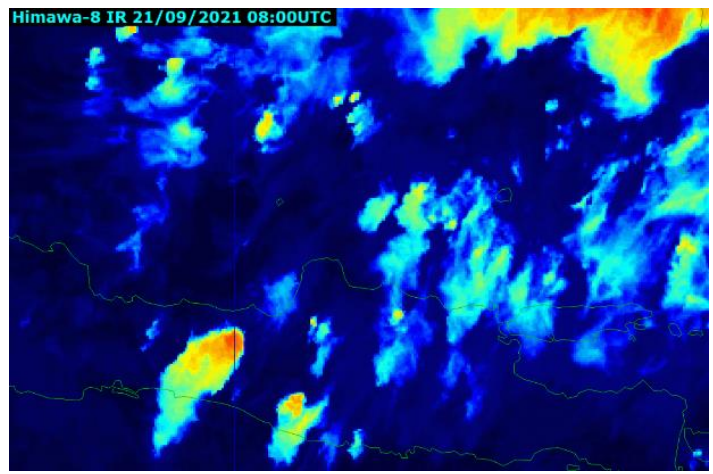

Gambar 10

Himawari-8 IR Tutupan Awan 09.00 UTC

Selanjutnya memasuki tahap disipasi. Dalam tahap ini butir-butir air yang akan ukurannya sudah mencapai batas maksimum akan turun sebagai air hujan sedangkan butir-butir yang masih kecil akan menguap kembali. Dalam kaitannya dengan awan cumulonimbus tahapan ini berlangsung sangat singkat dengan intensitas hujan yang tinggi. Dalam gambar tersebut dapat dilihat tutupan awannya terus menebal dan sudah berada dalam kondisi yang sangat tebal sehingga dapat dijadikan indikator bahwa pertumbuhan dan keberadaan awan-awan konvektif seperti awan cumulonimbus disekitaran wilayah Kota Bogor sudah ada.

2) Analisis Time Series

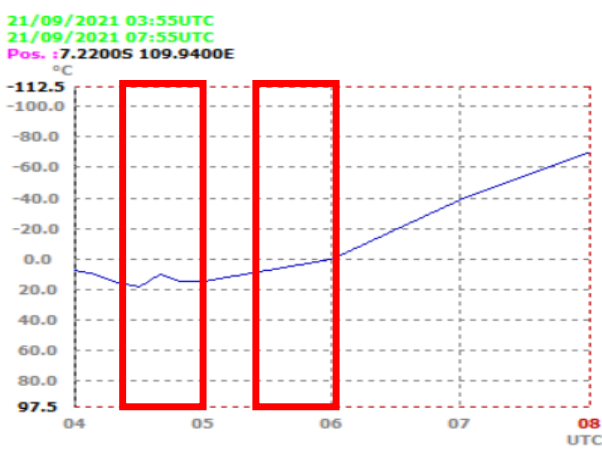




\section{Gambar 11 \\ Time Series Kanal IR}

Berdasarkan analisis time series suhu puncak awan pola suhu puncak awan di sekitaran wilayah Kota Bogor dapat terlihat bahwa suhu puncak awan pada pukul 04 UTC masih terlihat stabil dan mulai terjadi penurunan saat mendekati pukul 05 UTC tetapi masih fluktuatif perkembangannya. Pada pukul 05 UTC terus terjadi penurunan sampai pada angka 0o C pada pukul 06 UTC. Pada pukul 06 UTC terjadi penurunan yang signifikan secara terus menerus hingga pada pukul 07 UTC yaitu satu jam sebelum terjadinya kejadian angin puting beliung disekitaran wilayah Kota Bogor. Pada pukul 08 UTC dimana waktu terjadinya kejadian angin puting beliung suhu puncak awan mencapai nilai terendahnya selama empat jam terakhir.

3) Analisis Contour

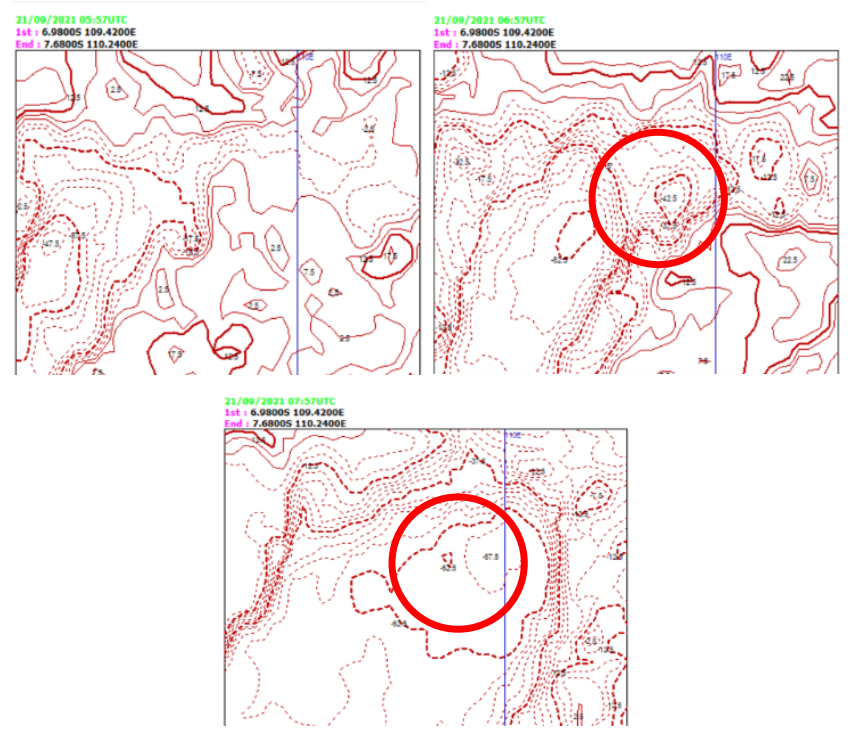

\section{Gambar 12}

\section{Peta Contour Suhu Puncak Awan}

Selanjutnya dilakukan analisis contour suhu puncak awan disekitaran wilayah Kota Bogor. Dapat terlihat pada pukul 05.57 UTC suhu puncak awannya masih normal tidak terjadi penurunan maupun penaikan. Pada pukul 06.57 UTC suhu puncak awan sudah mulai terjadi penurunan dan nilainya sebesar -42.5 untuk sekitaran wilayah Kota Bogor. Selanjutnya pada pukul 07.57 waktu terjadinya kejadian angin puting beliung disekitaran wilayah Kota Bogor suhu puncak awannya mencapai nilai berkisar antara 62.5 sampai -67.5 .

\section{Kesimpulan}

Dari hasil analisis penelitian ini maka dapat disimpulkan bahwa : 
1. Dalam analisis streamline angin telah terbentuk shearline pada pukul 07 UTC satu jam sebelum terjadinya kejadian angin puting beliung sehingga dapat dijadikan faktor terjadinya cuaca buruk atau kejadian ekstrem dalam hal ini kejadian angin puting beliung.

2. Selanjutnya untuk analisis $\mathrm{K}$ indeks dan $\mathrm{TT}$ indeks disekitaran wilayah Kota Bogor menunjukkan nilai berturut-turut sebesar 30-33 dan 40-42. Nilai tersebut menunjukkan dalam kategori sedang untuk terjadi cuaca buruk dapat berkaitan dengan kejadian angin puting beliung.

3. Untuk analisis Citra Satelit Himawari dalam kanal IR menunjukkan tutupan awan mulai menebal dua jam sebelum kejadian dan puncaknnya pada saat kejadian angin puting beliung tersebut. Selanjutnya dalam analisis timeseries IR dan contour suhu puncak awan satu jam sebelum dan saat kejadian terus menurun hingga mencapai nilai $-80^{\circ} \mathrm{C}$. 


\section{BIBLIOGRAFI}

Harsa, Hastuadi, Linarka, Utoyo Ajie, Kurniawan, Roni, \& Noviati, Sri. (2011). Pemanfaatan SATAID untuk analisa banjir dan angin puting beliung: studi kasus jakarta dan Yogyakarta. Jurnal Meteorologi Dan Geofisika, 12(2). Google Scholar

Prasetyo, Budi, \& Pusparini, Nikita. (2018). Pemanfaatan SATAID Untuk Analisa Atmosfer di Wilayah Perairan. JFA (Jurnal Fisika Dan Aplikasinya), 14(2), 37-44. Google Scholar

Saragih, Rino Wijatmiko Saragih. (2020). Analisis Kondisi Atmosfir, Indeks Labilitas, dan Citra Satelit Saat Kejadian Puting Beliung di Pontianak Kalimantan Barat (Studi Kasus 17 Juli 2020). Jurnal Fisika, 10(2), 62-71. Google Scholar

Silitonga, Andreas Kurniawan, Saragin, Immanuel Jhonson Arizona, \& Saragih, Rino Wijatmiko. (2017). DESKRIPSI PARAMETER CUACA DAN STABILITAS UDARA TERKAIT KEJADIAN ANGIN PUTING BELIUNG PONTIANAK (STUDI KASUS 30 AGUSTUS 2016). PROSIDING SEMINAR NASIONAL FISIKA (E-JOURNAL), 6, SNF2017-EPA. Google Scholar

Sudibyakto, H. A. (2018). Manajemen bencana di Indonesia ke mana? UGM PRESS. Google Scholar

\section{Copyright holder:}

Aqasha Raechan Anam, Sayful Amri (2021)

First publication right:

Syntax Literate: Jurnal Ilmiah Indonesia

This article is licensed under:

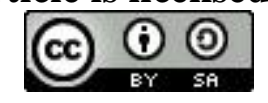

